\title{
Play-Based Mathematics in Kindergarten. A Video Analysis of Children's Mathematical Behaviour While Playing a Board Game in Small Groups
}

\author{
Rita Stebler • Franziska Vogt • Irene Wolf • \\ Bernhard Hauser $\cdot$ Karin Rechsteiner
}

Received: 1 April 2013 / Accepted: 11 June 2013 / Published online: 28 June 2013

(C) GDM 2013

\begin{abstract}
Kindergarten children enjoy playing games, as games bring motivation and active learning. Many board and card games require mathematical competencies and, therefore, carefully selected board and card games could be used as meaningful learning tasks for mathematics education in early childhood. With this in mind, several games for fostering quantity-number competencies have been implemented in an intervention study. The study included 6 years old children and three conditions: training program $(n=110)$, play-based intervention $(n=89)$ and control group $(n=125)$. For this article, videos involving 21 children in ten teams from one of the most widely played games in the play-based intervention were selected for in-depth analysis: the board game Shut the Box. This explorative analysis of children's mathematical behaviour and peer support whilst playing a board game allows researching in what way a specific game provides a meaningful learning task for early mathematics. The results show that children employ several mathematical skills while playing, depending on their individual quantity-number competencies. As the game can be easily repeated several times, the children practise and shape mathematical skills and monitor and support their co-player in order to increase their chances of winning the game. It is suggested that the board game provides an adaptive and motivating setting, which can meet the learning needs of low as well as high achieving children.
\end{abstract}

Keywords Quantity-number competencies · Play-based early mathematics · Early childhood education $\cdot$ Play $\cdot$ Video analysis

\section{Mathematics Subject Classification C70}

R. Stebler (凶) - I. Wolf

Institut für Erziehungswissenschaft, Universität Zürich, Freiestrasse 36, 8032 Zürich, Switzerland e-mail: stebler@ife.uzh.ch

F. Vogt · B. Hauser · K. Rechsteiner

Pädagogische Hochschule St. Gallen, Institut für Lehr- und Lernforschung, Notkerstrasse 27,

9000 St. Gallen, Switzerland 


\section{Spielintegrierte mathematische Förderung im Kindergarten. Eine Videoanalyse der mathematischen Aktivitäten der Kinder bei einem Regelspiel}

Zusammenfassung Kinder spielen gerne Regelspiele, denn Spiele motivieren und bieten vielfältige Lerngelegenheiten. Brett- und Kartenspiele mit mathematischem Potential könnten daher im Kindergarten als kognitiv aktivierende und adaptive Lernaufgaben zur Förderung des Zahlbegriffs eingesetzt werden. In einer Interventionsstudie mit sechsjährigen Kindern in 35 Kindergartenklassen und einem quasiexperimentellen Design mit drei Gruppen (Spielintegrierte Förderung: $n=89$; Trainingsprogramm: $n=110$; Kontrollgruppe: $n=125$ ) wurden 12 als mathematisch gehaltvoll erachtete Brett- oder Kartenspiele eingesetzt. Die spielenden Kinder wurden gefilmt. Für den vorliegenden Beitrag wurden die Videoaufnahmen zum Regelspiel Shut the box bzw. Klipp-Klapp (21 Kinder in 10 Teams) analysiert, um das Potential dieses Spiels als kognitiv aktivierende Lernaufgabe zu untersuchen. Die Ergebnisse dokumentieren ein breites Spektrum mathematischer Handlungen. Die Handlungen variieren mit den individuellen Mengen-Zahlen-Kompetenzen der Kinder. Die Kinder beschäftigen sich in den Spielphasen fast ausschliesslich mit Mathematik. Sie überwachen die Spielzüge der Partner und unterstützen einander. Diese Befunde legen den Schluss nahe, dass das Regelspiel Shut the Box ein adaptives Lernarrangement ist, das den Lernbedürfnissen leistungsschwacher und leistungsstarker Kinder entgegen kommt und zudem eine hohe Übungskadenz und soziale Unterstützung beim Aufbau von Mengen-Zahlen-Kompetenzen gewährleistet kann.

\section{Introduction}

Research into early childhood education has shown repeatedly the great importance of that phase for later learning in school and beyond. Children entering formal education in primary school have a wide range of precursory knowledge. This also applies to mathematics (Hengartner and Roethlisberger 1995; Moser Opitz 2001; Weinhold Zulauf et al. 2003): whereas approximately $20 \%$ of the children have already mastered the learning goals for the school year ahead and $60 \%$ demonstrate the competencies of year 1 to a large extent, a minority of children have great difficulties and might not know how to count or might not recognise numbers (Moser et al. 2005). Precursory mathematical knowledge shown at the end of kindergarten accounts for $17 \%$ of the variance at the end of year 3 of primary school, more than cognitive ability $(10 \%)$ or age $(7 \%)$ or socio-economic background $(4 \%)$ (Moser and Bayer 2010). Mathematical precursory knowledge even predicts mathematical competency at the end of year 4 (Krajewski and Schneider 2006). Heterogeneity of the mathematical competency at the beginning of primary school continues, and the gap between the most and the least competent students increases (Fogelman 1983). In general, pre-knowledge has proven to be a crucial factor to determine knowledge acquisition (Helmke and Weinert 1997). With the aim of increasing equal opportunities and the fostering of all children it becomes paramount to systematically support the acquisition of mathematical precursory knowledge in kindergarten (Krajewski and Schneider 2006; Grüßing and Peter-Koop 2008). While learning about structures, regularities 
and comparisons relevant for mathematical learning starts with birth (Dehaene 1997; Hirschmann et al. 2008), early childhood education in kindergarten offers an introduction to mathematical verbalisation and mathematical reasoning. Four to six years old children indeed show an enormous progress in their mathematical competency (Weinhold Zulauf et al. 2003). These insights have informed the curricula which guide kindergarten practice. Recent curricula for the early years generally include mathematical learning goals and centre on the acquisition of quantity-number competencies $^{1}$ defined as a combination of knowledge, skills and attitude (Projekt Deutschschweizer Lehrplan 2010). This raises the questions of how quantity-number competencies can effectively be fostered in Kindergarten and leads to the development of the play-based approach adopted in our research.

The literature review addresses the foundations for this research discussing early quantity-number competencies, play-based teaching and learning arrangements for fostering mathematics in kindergarten as well as the potential of games as meaningful learning tasks. Then the methodology is presented, describing the design, the game chosen for this analysis, and the procedure for analysing the video data. The result section shows in depth the findings around children's mathematical behaviour and also addresses aspects such as play and support. The discussion brings together the findings on the potential of the game Shut the Box for fostering early quantity-number competencies with the prospects of games as adaptive and meaningful learning tasks in general.

\section{Play-Based Teaching-Learning Arrangements for Early Mathematics}

\subsection{Early Quantity-Number Competencies}

Quantity-number competencies are at the heart of the mathematical sense making for young children of four to six years (Krajewski and Schneider 2009). Children's early quantity-number competencies are highly relevant for later mathematical learning (Jordan et al. 2009). These important competencies are understood and named in different ways within the research literature. In educational psychology knowledge and skills related to numbers and quantities acquired in early childhood are often termed number sense (Dehaene 1997), early numeracy (Aunio et al. 2009), numerical competency (Resnick 1989) or number competencies (Jordan et al. 2009). Common key elements of the denoted concepts include counting, number knowledge and arithmetic operations. More specifically and according to Jordan et al. (2009) early "number competencies refer to the ability to apprehend the value of small quantities immediately, make judgements about numbers and their magnitudes [...], grasp counting principles [...], and join and separate sets [...]. They also involve a linear representation of small numbers, such that each number is one more than the one that comes before it or one less than the one that comes after" (p. 851).

\footnotetext{
${ }^{1}$ Since compulsory education in Switzerland begins with kindergarten at the age of four years old and as curricula are competence-based, the term 'mathematical precursor' is no longer suitable in this pedagogical context.
} 
Quantity-number competencies are built on inherent number and magnitude systems (Siegler et al. 2011). The development starts with precise representations of small numbers in the preverbal infant and occurs in absence of formal instruction. Between ages 2 and 5 years children learn to count and acquire a symbolic system for representing numbers. At this stage, when children are assumed to map counting words and Arabic numerals onto nonverbal quantities as a basis for later learning of more complex mathematical competencies, verbal input and instruction are essential (Jordan et al. 2010). Among others, Krajewski and Schneider (2009) proposed a theoretical model to show how early mathematical competencies are acquired via linking imprecise nonverbal quantity concepts with the ability to count. The model describes three developmental levels:

(1) Basic Numerical Skills.

Children have an innate capacity to discriminate quantities. With language development they start using words such as more or less for quantity discrimination and they acquire precise number words and the exact number-word sequence. Number words are not used yet to describe quantities.

(2) Quantity-number concept.

Linking number words with quantity is performed in two steps. Children start with assigning number words to rough quantity categories (imprecise quantity to number-word linkage) and gradually come to match the exact number-word sequence to precisely arranged quantities (Precise quantity to number-word linkage). Furthermore, children learn from experience "that a quantity can be divided into pieces that, taken together, equal the original quantity [...] and that quantities change only if something is added or taken away" (Krajewski and Schneider 2009, p. 519).

(3) Concept of number relationships.

Children come to understand the decomposition of numbers and the differences between numbers. With growing quantity-number competencies children's mathematics transform from something that can only be done by manipulating real objects to something that can be done in their heads (Griffin 2004).

Observed outcome of early quantity-number competencies includes subitizing, comparing of numerical magnitude, counting and performing simple arithmetic calculations. Subitizing relates to fast verbal naming of small quantities without counting the items separately (perceptual subitizing) or to instant recognition of a structured quantity (conceptual subitizing; Clements 1999). Numerical magnitude comparison refers to processes, where either an approximate (more, less, equal) or an exact evaluation of magnitudes or symbols representing magnitudes is used. It has been shown that the ability to process numerical magnitude information is crucial for mathematics development (Siegler et al. 2011). To count the child has to know the number names and the count sequence. Counting also involves the knowledge of counting principles: the one-to-one principle, the stable-order principle, the cardinal principle, the abstraction principle, and the order-irrelevance principle (Gelman and Gallistel 1978). Depending on their mathematical development children apply different counting strategies starting from Counting All from First (CAF)/Last (CAL) (Baroody 1995) to Counting On First (COF)/Last (COL) (Hopkins and Lawson 2002). Simple arithmetic calculations pertain to the mental processes and structures including 
the part-whole concept required for simple arithmetic operations such as addition or subtraction (Ashcraft 1995).

As stated in the introduction above, the differences in competency levels for early mathematics are highly relevant for future educational outcomes. With the aim of fostering equal opportunities, it is therefore highly relevant to find adequate and effective ways to support the development of quantity-number competencies in kindergarten.

\subsection{Fostering Early Quantity-Number Competencies}

Over the last decade a wide range of programmes and teaching materials has been developed for mathematical learning in early childhood education. In German speaking Switzerland kindergarten teachers have adopted diverse approaches: Zahlenland (Follow me into the land of numbers) by Friedrich et al. (2011) is widely used, as well as Zahlenbuch Frühförderung by Wittmann (2009) from the programme Mathe 2000, and Mengen zählen Zahlen (Quantities, counting and numbers) developed by Krajewski et al. (2007). Findings of evaluations are inconclusive: Pauen and Pahnke (2008) compared Mathe 2000 with Zahlenland and concluded that the approaches do not differ in their effectiveness. Krajewski et al. (2008) found better effects for Mengen zählen Zahlen compared to Zahlenland, however, the comparison group was not controlled within a quasi-experimental design. Some authors have, however, questioned whether a highly instructional learning setting within early childhood education will have the desired positive effects in the long term (Dollase 2010; Hauser 2005) and have emphasised the importance of play for learning and the need for playfulness in early mathematics (Singer et al. 2009). Marcon (2002) found more positive effects at the end of primary school for children who had benefitted from a child-centred and playful learning setting in early childhood education and negative effects for early instructional school-like settings. Several authors have also proposed the use of games to improve children's basic number skills and enhance their motivation during mathematics learning (Ainley 1990; Bragg 2003; Peters 1998; Schuler 2013; Ramani and Siegler 2011; Van Oers 2010). Dice games have been found to increase children's counting skills (Hughes 1986; McConkey and McEvoy 1986). Peters (1998) found in an intervention study that the intervention group where children played games in small groups developed better precursory mathematical competencies than the group of children, who did not play games as part of the intervention. Our own intervention study with a quasiexperimental design also found better effectiveness of play-based mathematical fostering (Spielintegrierte Mathematische Förderung $=\mathrm{SpiF}$ ) as compared to the traditional kindergarten teaching, whereas a training programme (Mengen zählen Zahlen; Krajewski et al. 2007) did not show effects (Rechsteiner et al. 2012).

\subsection{Games as Meaningful Mathematical Learning Tasks}

Having established the importance of fostering quantity-number competencies in kindergarten and having discussed the potential benefits of playing games with mathematical benefits we turn to an analysis of play-based teaching-learning arrangements for early mathematics. According to Reusser (2011) productive learning facilities evolve from the interplay of a meaningful learning task, an adaptive teaching method and supportive interactions by teachers or peers. 
Meaningful Learning Tasks Learning tasks have a strategic role in instructional processes since they activate and guide student learning (Blömeke et al. 2006). This applies in particular for teaching heterogeneous groups of learners, where the tasks need to meet the level of competency of the individual child-with regards to mathematics as well as self-regulation (Reusser and Stebler 2012). Reusser (2006) highlights the following characteristics of meaningful learning tasks: (i) Meeting heterogeneous learning need: Meaningful learning tasks can be worked on with different competency levels and should allow for different learning strategies. (ii) Content, activation, co-operation and problem-solving: Meaningful learning tasks should represent the core ideas of the subject, invite exploration and be authentic and motivating. This can often be found in tasks which are linked to daily life experience, include puzzles or draw upon humour. Co-operative and interactive forms of learning also support motivation. Meaningful learning tasks have the following mathematical characteristics, according to Wittmann (2010): (i) Elements (entities) are provided, which can be mathematically defined and which are in mathematical relations to each other. (ii) The elements can be dealt with using mathematical rules. (iii) The mathematical activity has an aim. It therefore always includes the examination of patterns and orders and problem-solving through the use of these structures. (iv) The mathematical learning activities need to be a foundation for the future learning processes. This involves for example a careful choice of number representation to ensure that the representations used in kindergarten are those used at school too. Learning outcome depends on the quality of in-depth learning processes: the more active, motivated, self-regulated, problem-oriented, reflected, linked with pre-existing knowledge as well as interactive the learning process is, the better is the learning outcome in terms of understanding (transparency, clarity), stability, transferability, and in terms of positive emotions such as motivation, interest and self-efficacy (Reusser 2006).

Play as a Powerful Teaching Method For kindergarten, play provides a context for activating and self-directed learning (Hauser 2013). Often children have better learning outcomes when they are learning through play in pre-school rather than through instructional and formal teaching (Dollase 2010). Vygotsky coined the poetic saying: "In play a child is always above his average age, above his daily behavior; in play it is as though he were a head taller than himself" (Vygotsky 1978, p. 129). In German speaking Switzerland, pedagogy of the kindergarten is strongly related to the concept of free play. This emphasis on play rather than school-like formal instruction could contribute to fostering mathematical competencies. However, play does not work automatically and finding a good balance in the curriculum in early childhood is a great challenge to educators (Wood 2011). The requirements for a meaningful learning task as outlined above could also be used to select games for play-based teaching-learning arrangements for early mathematics.

For fostering quantity-number competencies board and card games can be particularly helpful. Board and card games require only short instructions at the outset and afterwards, the children can play very independently. Bright et al. (1985) mention the voluntary nature of a game, the challenge through the opponent and through the task, the set of rules which regulate the process, the options and the goal, the distinct nature of a game as different from real life, the low stakes for all players, and a defined end 
with the unknown episodes. Educational board games are often praised for fostering arithmetic skills. Some research has also proven the effectiveness of certain games for quantity-number competencies, as for example Siegler et al. (2011), Whyte and Bull (2008) and Obersteiner (2012). Card and board games also allow for the deepening of competencies already acquired: "in a game there is a context for using some mathematics that you have learned, and that context is real for children because they can engage with it and the outcome matters to them" (Ainley 1990, p. 86). Card and board games can be played at different stages of mathematical competencies. Kamii and Kato (2005) show in a detailed analysis of 'lining up the fives' how less advanced children do not think ahead for the future steps in the card games, whereas more advanced children show more strategic decisions, which make thinking ahead necessary. Kamii and Kato (2005) conclude that card and board games can foster development in varied and powerful ways. The opportunity a game offers is taken up in relation to the situation and the individual preconditions (Schuler 2013). To have motivating learning arrangements is ever so important: "it is not possible for adults to foresee exactly how children will develop their logico-mathematical network, but it is possible for us to provide them with rich activities that will motivate them from within to think hard" (Kamii and Kato 2005, p. 382). However, there is only little research on the ways children use materials provided. Children often are not using the materials in the way they were/are intended (Ginsburg and Golbeck 2004). "A rich physical environment by itself is not enough. The crucial factor is not what the environment makes possible, but what children do in it" (Ginsburg et al. 2008, pp. 6-7). The analysis of the children's actions and interactions while playing the games enables understanding the potential of the games for mathematical learning.

Interaction and Support Socio-constructivist learning theories have highlighted the fact that all learning is socially embedded; that sense making can only be understood as part of a dialogue with others (Reusser 2001). In line with socio-constructivism the importance of collaborative learning arrangements has become more and more apparent. While playing games in small groups, the children interact with each other; the games provide an opportunity for mathematical talk. According to Osana and Rayner (2010) it can be expected that verbalisation of mathematical thinking has a positive impact on children's mathematical understanding. Boonen et al. (2011) reported that a too diverse mathematical talk by the teacher has a negative effect. They conclude that mathematical talk through the teacher should be carefully and selectively employed. In contrast, the mathematical talk required when playing a board or card game together is constructed by the children themselves. In playing together, children monitor their own behaviour as well as the behaviour of the other children. They monitor the learning process, provide feedback, notice errors and help each other in developing deeper understanding. Research into collaborative settings has shown that although there is great potential, collaborative learning does not per se lead to good learning outcomes. Collaboration requires competencies, successful collaboration needs to be learned (Gillies and Haynes 2011; Howe et al. 2007). We envisage that playing games in small groups provides a motivating arrangement to learn to collaborate and to learn collaboratively. 


\subsection{Research Questions}

Drawing on the relevance of the development of quantity-number competencies for mathematical learning and on the importance of high quality teaching and learning arrangements this study aims at investigating the potential of a selected board game, namely Shut the Box. The following research question is at the heart of this explorative study: What behaviour do six years old children show while playing the selected board game? Three sub-questions are addressed:

(i) What mathematical behaviour do the children show?

(ii) Is there a correlation between the arithmetic strategies employed in the game and the overall test score?

(iii) What behaviour regarding play and support can be observed?

\section{Methods}

\subsection{Design and Sample}

The videos analysed in this study are part of the data of the research project 'Fostering mathematical precursory competencies with six years old children: training programme or play-based approach? (SpiF)'. Thirty-five kindergarten classes from the St. Gallen Region in Switzerland took part in the SpiF project. From these 35 classes, all children in the second year of kindergarten with the average of 6:3 years participated $(n=324)$. The classes were recruited randomly from the cantonal list of kindergartens and teachers were asked at random to take part in one of three conditions. 11 classes with 89 children received the play-based approach (Hauser et al. 2010; Vogt 2012), 12 classes including 110 children were given the training programme by Krajewski et al. (2007) and 12 classes with 125 children formed the control group. The teachers of the two intervention groups received two days of teacher training in the respective methods of fostering mathematical competency in kindergarten. Only at that moment they became aware that there are two different interventions. The interventions were implemented by the teachers in 24 units of half an hour each, over the time of 8 weeks in spring 2010. The duration and the timing of the intervention towards the end of kindergarten followed the guidelines of the training programme by Krajewski et al. (2007).

Mathematical competency of the children was measured as part of a pre- and posttest design, using the test by Moser and Berweger (2007). This test was developed for a longitudinal study and standardised with 1000 children in German speaking Switzerland. It covers the understanding of the ordinal aspect from using pictures to tasks with numbers only, and similarly the cardinal aspect, and it includes tasks comparing amounts, naming numbers and operations supported with pictures (addition, subtraction) and addition and subtractions with numbers only. The tasks in the test are embedded in a story and illustrated with pictures. The mathematical competency test was carried out by a researcher on a one-to-one basis in the rooms of the kindergarten.

For the play-based intervention, 12 board and card games were used. For most of the time, children were given free choice for selecting a game and forming groups 
with their peers. However, the intervention can be seen as guided play (Golinkoff 2010) as only these games for fostering early mathematics were on offer during the half an hour unit. The duration of the intervention was controlled as the games were not available for children during other times, for example free play. In approximately the fifth or sixth week of the intervention, the research team visited the class during one half an hour sequence and videoed with five fixed cameras the interactions of the children playing.

From the video data, ten sequences depict children playing the game Shut the Box. These videos will be analysed in depth here. The video sequences include 21 children (10 girls, 11 boys; $M=6: 3$ years, $S D=4$ months) in seven kindergarten classes playing in pairs (nine groups of pairs) and in a group of three children. The filmed children (= Shut the Box sample) have reached a pre-test score of $70.8(\mathrm{SD}=20.6)$ and a significantly higher post-test score of $83.1(\mathrm{SD}=19.1 ; t=-5.47, \mathrm{df}=19$, $p<.001)$.

\subsection{The Shut the Box Game}

The game Shut the Box (www.carlit.ch) is played with dice and a box with wooden tiles showing the numerals 1 to 9 (Fig. 1). The aim is to shut down all numeral tiles. The player who achieves this first is the winner. Many variations are known; the game is recommended from kindergarten age onwards, can be played by two or more players and requires luck (dice), arithmetic skills and strategy (Wikipedia 2012). For this research project we defined specific rules, which would support young learners in playing the game. In this specific variation of the rules of the game, each player has his or her own box with the numerals on the tiles. After each episode of throwing the pair of dice once and-if possible-shutting a number tile, the co-player continues. In this set up, the children are active at regular intervals and are not required to watch the co-player play for a long time. Different to other variations, the players only decide to shut the tile of the sum of the two dice, or the tally of each separate dice, but not other combinations. If any of these three options are already shut, nothing can be done in this episode, and the co-player continues throwing his or her pair of dice. The kindergarten teacher was provided with a manual of all the games and thus introduced the game briefly to the class. The children then played the game without help of the teacher.

Fig. 1 The Shut the Box game

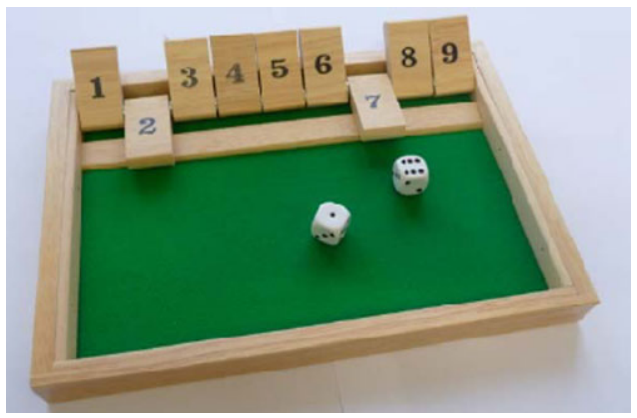


The following actions are required in this game:

- throwing the pair of dice,

- defining the tally,

- defining the options: tally of dice A, tally of dice B or the sum of A and B,

- comparing the options with the numeral tiles of the box,

- selecting one option and shutting a tile.

Drawing on the findings and theories on the development of quantity-number competencies as discussed above, we envisage that many different strategies related to meaningful arithmetic learning can be employed for playing this game. Defining the quantity can be achieved through counting, subitizing or adding, among other ways. The following transformations are needed: From the iconic representation with the dots on the dice to the verbalised number (spoken out aloud or thought) and further to the quantity represented through the numeral (either the child recognises the numbers or the child counts the tiles to find the correct numeral tile). Defining the options (tally of dice A, tally of dice B or the sum of A and B) refers to the part-whole concept.

\subsection{Procedure of Data Analysis}

For the analysis of the video data a strategy based on content analysis (Mayring 2007) was employed. The units of analysis were defined, categories and a coding procedure were developed.

\subsubsection{Units of Analysis}

Round: A round begins with the first throwing of the dice by one of the children and ends with one of the children completing the game and winning.

Episode: As the children take it in turn to play, an episode is defined by these turns. An episode begins with one child being the player, throwing the dice, counting, shutting down number plates, and ends with the change of role, when the other child plays.

Action: An episode contains severeal actions, such as shutting down no number, shutting down one or two number tiles, counting, adding, counting the amount for the other child, correcting the other child.

Turn: In order to examine peer interaction at play, turns are also used as a unit of analysis. A turn is defined as the utterances of one child before the next one speaks.

\subsubsection{Categories}

To develop the categories, episodes were rated on the following aspects: (1) arithmetics, (2) playing, and (3) peer interaction. Table 1 provides an overview of the aspects, dimensions, categories and variants. 


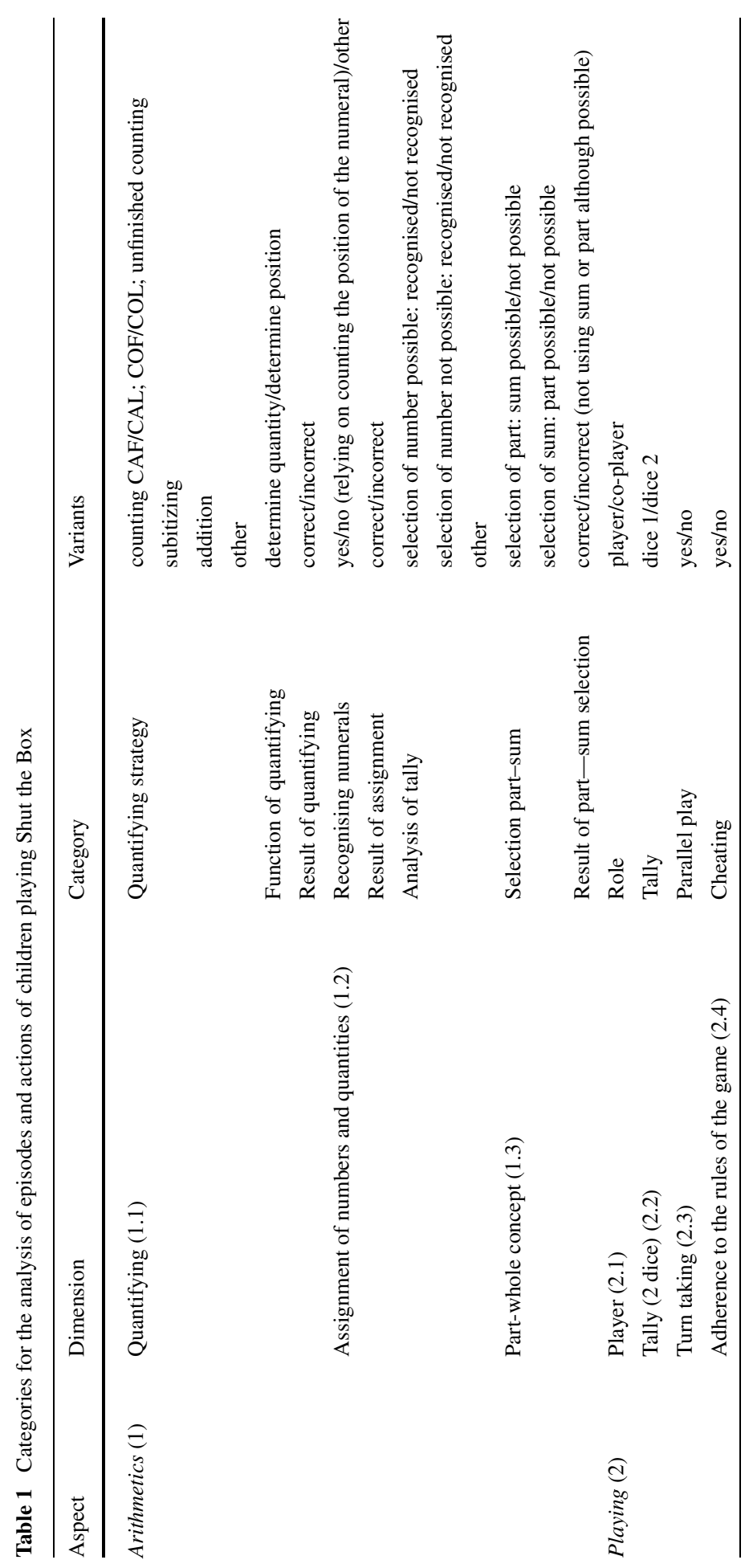




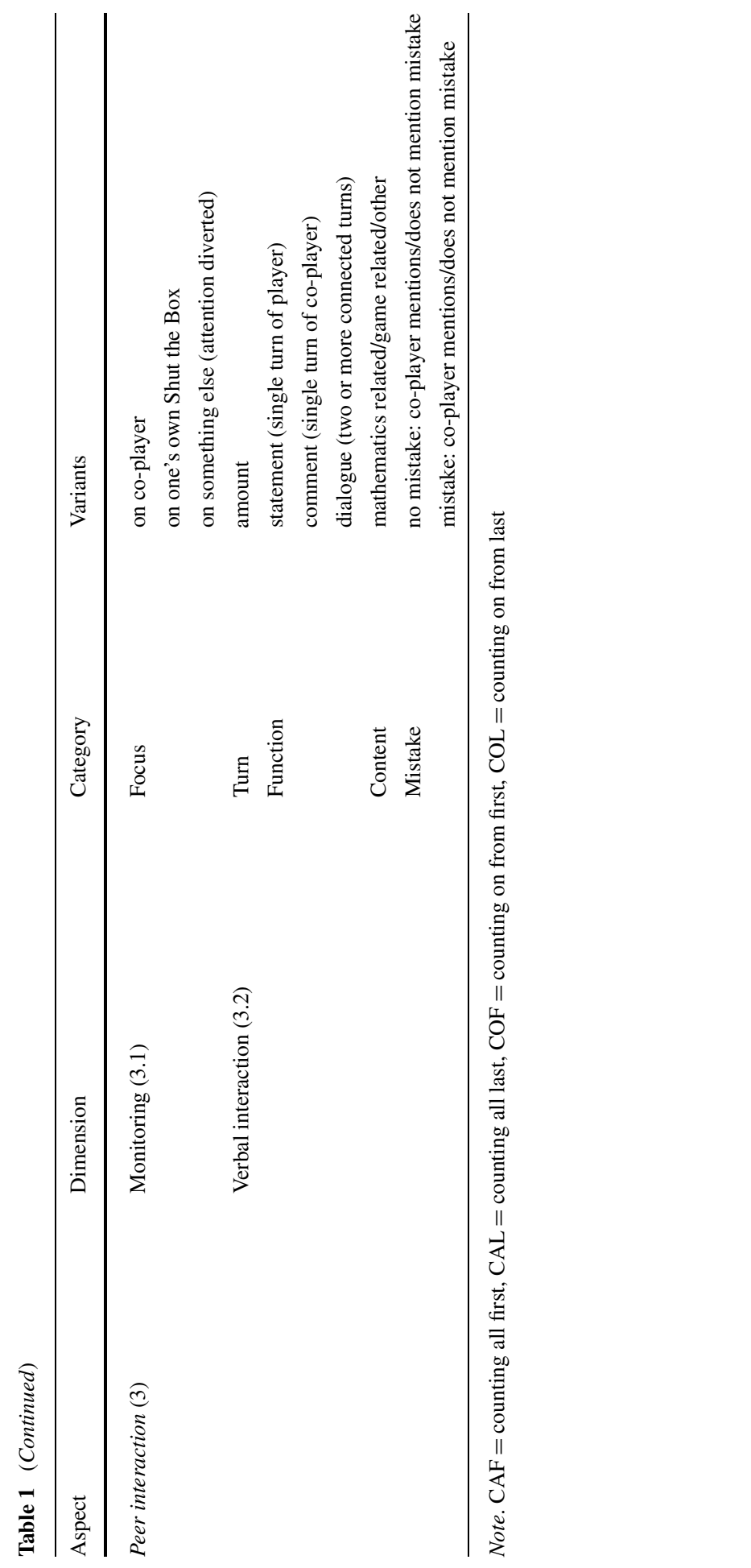


Arithmetics (1) The mathematical actions in each episode are categorised along the dimensions quantifying (1.1), assignment of numbers and quantities (1.2) and partwhole concept (1.3).

The dimension quantifying (1.1) involves counting (counting all first (CAF), counting all last (CAL), counting on from first (COF), counting on from last (COL) or unfinished counting), addition, subitizing or other. Addition is given when the child figures out the sum trough verbalising summands, operator and result. Subitizing is coded when the child quickly verbalises the number of dots on one dice or the sum of dots on two dice (neither counting nor addition is observed) or when the child quickly acts accordingly, as for example when the child shuts down the number in the box as soon as the dice has fallen. Subitizing involves two types of strategies: it entails the perception of small numbers of dots $(\leq 4)$ and also the recognition of structured patterns of dots. Other is coded for situations where neither subitizing nor counting or adding is visible. In these cases it remains unclear, what strategy the child employs. Finally when the child has a tally, which does not allow for shutting down a number (for example the child would only need the number 9), often quick assessment without counting or without stating the number is sufficient.

The categories of the dimension assignment of numbers and quantities (1.2) focus the process of the representation and the comparison of quantity. The category recognising numerals looks at transforming iconic (dots) or acoustic (number-words) representations of numbers into symbolic representations (numerals). Children with number recognition can make a simple transfer from the iconic or acoustic representation to the symbolic representation. Children who do not recognise a numeral right away can use counting the number tiles to find the position of a number within the series. As above, the number recognition is rated as correct or incorrect. As there are several options of using the tally in a given situation during the game, even more transfer is required. The child has to decide, which tile to shut down. Also this decision is rated as correct or not incorrect.

Within dimension part-whole concept (1.3) the analysis focuses on the choice of the child during an episode. The child often has the choice of either choosing a part (tally of dice 1 or tally of dice 2) or the sum of the tallies. The various options are coded in the category selection part-sum (selection of part when sum is possible/not possible; selection of sum when part is possible/not possible). Two strategies can be distinguished: the choice of the sum whenever possible and the choice of the part whenever possible. Again, the result of the part-sum selection is coded as to whether it is correct or not.

Playing (2) For this aspect, the following indicators were defined: the role of each child (player versus co-player) (2.1), the tally of the two dice (2.2), turn taking (parallel play yes/no) (2.3) and adherence to the rules of the game (cheating yes/no) (2.4).

Peer Interaction (3) The dimension monitoring (3.1) examines, whether or not the co-player observes the actions of the player. This is rated using the direction of their gaze, whether the co-player looks in the direction of the action of the co-player, his or her own shut box or to something else. The dimension verbal interaction (3.2) in- 
cludes several categories: First, the number of turns is counted. A turn begins with the change of speaker and ends with the last word before the next child speaks, or the action of the next player. Counting aloud is not regarded as a turn. If an episode includes turns, then the interactive function is coded: Statement is coded as a verbalisation of one player which is not followed by the response of the next player, commentary is given as a verbalisation of the co-player which is not followed by a response of the player. Two or more connected turns are coded as dialogue. If possible the content of the verbal interaction is analysed, distinguishing between verbalisations related to the mathematical content, to the game or other verbalisations. Mathematics related content is coded with regard to the arithmetical aspects quantifying, assignment of numbers and quantities or part-whole concept. Game related content includes the rules of the game, the course of the game, the score or statements related to cheating. Finally, the category mistake is given for capturing error detection.

\subsubsection{Coding Procedure}

For coding, first the segmentation of the video sequences into rounds and episodes was completed. Following the segmentation, for each episode the actions were defined. The categorisation first focussed on the aspect of playing. Then each action was coded according to arithmetics and finally the peer interaction was analysed.

\subsubsection{Method of Data Analysis}

The analysis was conducted directly whilst watching the video. Only certain illustrative examples of episodes were transcribed. The codes were entered into an SPSS data file. Coding was completed in December 2010, a reliability check was carried out six months later. To test the reliability 72 out of 634 episodes were randomly chosen and recoded by the same rater. Intra-rater reliability was overall high (Cohen's Kappa $>0.90)$. Slightly lower reliability was found for the categories quantifying strategy, turn and function (0.87) and mistake (0.84). The statistical analysis was done using SPSS.

\section{Results $^{2}$}

\subsection{Descriptives}

The 10 groups of 21 children played 22 rounds of the game Shut the Box in total. Groups played between one and six rounds (Table 2). The video data analysed includes $1 \mathrm{~h} 51 \mathrm{~min} 53 \mathrm{~s}$. On average a round had the duration of five minutes $(\mathrm{M}=5 \min 5 \mathrm{~s} ; \mathrm{SD}=2 \min 3 \mathrm{~s})$.

\footnotetext{
${ }^{2}$ The results for this paper are part of the master thesis of Irene Wolf (2011), which she completed in the context of the project "Fostering precursors in mathematics for six years old children: training programme versus play-based fostering — SpiF" (project supported by the Swiss National Science Foundation).
} 
Table 2 Descriptive data related to the videos analysed in the study

\begin{tabular}{|c|c|c|c|c|c|c|c|}
\hline Group & $\begin{array}{l}\text { Child } \\
\text { (Number) }\end{array}$ & Round & $\begin{array}{l}\text { Duration } \\
\text { h:min:s }\end{array}$ & Episode & Action & $\begin{array}{l}\text { Maths competency } \\
\text { pre-test }\end{array}$ & $\begin{array}{l}\text { Maths competency } \\
\text { post-test }\end{array}$ \\
\hline \multirow[t]{2}{*}{1} & 22 & 6 & $27: 44$ & 164 & 98 & 35 & 56 \\
\hline & 23 & & & & 87 & 68 & 71 \\
\hline \multirow[t]{2}{*}{2} & 231 & 1 & $9: 44$ & 40 & 25 & 51 & 56 \\
\hline & 271 & & & & 25 & 47 & 82 \\
\hline \multirow[t]{2}{*}{3} & 21 & 1 & 9:03 & 18 & 11 & 52 & 67 \\
\hline & 29 & & & & 9 & 46 & 62 \\
\hline \multirow[t]{2}{*}{4} & 201 & 1 & $4: 43$ & 17 & 10 & 69 & 66 \\
\hline & 241 & & & & 13 & 84 & 90 \\
\hline \multirow[t]{2}{*}{5} & 28 & 4 & $15: 53$ & 154 & 84 & 71 & 86 \\
\hline & 30 & & & & 80 & 49 & 70 \\
\hline \multirow[t]{3}{*}{6} & 24 & 2 & $14: 19$ & 67 & 24 & missing & missing \\
\hline & 25 & & & & 28 & 90 & 107 \\
\hline & 27 & & & & 22 & 72 & 74 \\
\hline \multirow[t]{2}{*}{7} & 212 & 1 & $7: 50$ & 30 & 21 & 79 & 111 \\
\hline & 262 & & & & 20 & 66 & 73 \\
\hline \multirow[t]{2}{*}{8} & 211 & 1 & $4: 57$ & 26 & 17 & 74 & 83 \\
\hline & 261 & & & & 18 & 75 & 81 \\
\hline \multirow[t]{2}{*}{9} & 281 & 3 & $10: 35$ & 67 & 40 & 82 & 94 \\
\hline & 291 & & & & 49 & 103 & 111 \\
\hline \multirow[t]{2}{*}{10} & 20 & 2 & 7:05 & 51 & 29 & 120 & 120 \\
\hline & 26 & & & & 29 & 83 & 101 \\
\hline Total & & 22 & $1: 51: 53$ & 634 & 739 & & \\
\hline
\end{tabular}

The 22 rounds included 634 episodes $(\mathrm{M}=28.81$; $\mathrm{SD}=11.28)$, which consist of 739 actions. $14 \%$ of the episodes included two or more actions: second move according to a teacher-initiated modification of rules $(n=24)$, supplementary quantifying e.g. for checking results $(n=42)$, correcting move $(n=9)$, quantifying by the co-player $(n=30)$. Three actions could not be coded because of problems with the quality of the video. For analysis 736 actions were included. On average, a child performed 35 actions $(\mathrm{M}=35.19 ; \mathrm{SD}=27.01)$. The range of actions is large. It ranges from 9 to 99 actions per child. The children of this sample had a mean pre-test result of $70.8(\mathrm{SD}=20.6)$ and a mean post-test result of $83.05(\mathrm{SD}=19.1)$. The minimum in the pre-test was 35 , the maximum 120 . In the post-test the minimal score obtained was 56, the maximal score 120 (Table 2). The Shut the Box sample significantly improved from pre- to post-test $(t=-5.47, \mathrm{df}=19, p<0.001)$. At this point, it should be noted that Shut the Box was one out of 12 games played by the children of our sample during the play-based intervention. Therefore, learning gains and individual differences cannot be explained by the mathematical behaviour when playing Shut the Box, neither for groups nor for individuals. 
Table 3 Quantifying strategy

\begin{tabular}{lllc}
\hline Quantifying strategy & Actions & & \\
\cline { 2 - 4 } & Total & $\begin{array}{l}\text { Shutting number } \\
\text { tile possible }\end{array}$ & $\begin{array}{c}\text { Shutting number } \\
\text { tile not possible }\end{array}$ \\
\hline Counting (352/719) & & & 162 \\
CAF, CAL & 275 & 113 & 32 \\
COF, COL & 47 & 15 & 8 \\
Unfinished counting & 27 & 19 & 0 \\
Counting not coded & 3 & 3 & 96 \\
\hline Without counting (367/719) & & 26 & 75 \\
Subitizing & 122 & 55 & 8 \\
Addition & 130 & 107 & 381 \\
Unknown quantifying strategy & 115 & 338 & \\
\hline Total & 719 & & \\
\hline
\end{tabular}

Note. All actions except those in which the position of the tile is determined by counting $(17 / 736)$. CAF $=$ counting all first, $\mathrm{CAL}=$ counting all last, $\mathrm{COF}=$ counting on from first, $\mathrm{COL}=$ counting on from last

\subsection{Observed Mathematical Behaviour}

As described above, after having thrown the dice, the child needs to quantify the dots with respect to parts (two subsets; dice 1, dice 2) or the whole (sum). The child can count or use strategies such as subitizing or addition. Then the child needs to compare the arithmetic result with the tiles on the box of the game and shut down one tile. To identify the numerals on the tiles, the child could rely on number recognition or identify the serial position by counting.

Quantifying From all 736 actions, half of the actions involve counting (369/736) (Table 3). Counting is mainly used to define the sum of the two tallies (350/369), twice, counting action was used to define a part tally (2/369) and 17 times, counting helped to determine the position of the tile (17/369). The other half of all actions does not involve counting, but other strategies for quantifying $(367 / 736)$. A third of these actions with quantifying strategies involve "subitizing" (122/367), "addition" (130/367) or "unknown quantifying strategy" (115/367).

Two situational aspects can be distinguished regarding the episodes: Situations, where the tally could result in a number tile being shut down and situations, where the tally cannot be used to shut down a tile, because all three possible numbers have already been shut down. 338 actions occur in the context of episodes, where it would be possible to shut a number tile, 381 actions are in the context of no such possibility. In situations, where shutting a number tile is possible, counting is less frequent $(150 / 338 ; 43 \%)$ than in situations, where shutting a number tile is not possible $(202 / 381 ; 53 \%)$.

In the majority of actions $(275 / 352 ; 78 \%)$, in which the sum of the two tallies is determined by counting, children count through both dice either starting with the dice with the smaller tally (counting all from first, CAF) or starting with the dice with the 
Table 4 Partial correlation between sum of the two tallies and the quantifying strategy

\begin{tabular}{|c|c|c|c|c|c|}
\hline \multirow[t]{2}{*}{ Control variable } & \multirow[t]{2}{*}{ Variable sum } & & \multicolumn{3}{|c|}{ Variable quantifying strategy } \\
\hline & & & $\mathrm{CAF} / \mathrm{CAL}$ & $\mathrm{COF} / \mathrm{COL}$ & Addition \\
\hline \multirow[t]{3}{*}{ Pre-test \& post-test ${ }^{\mathrm{a}}$} & Sum of the two tallies & Partial correlation & $r=0.216$ & $r=0.169$ & $r=-0.294$ \\
\hline & & significance (2-tailed) & $p<0.01$ & $p<0.01$ & $p<0.001$ \\
\hline & & df & 246 & 246 & 246 \\
\hline
\end{tabular}

Note. $\mathrm{CAF} / \mathrm{CAL}=$ counting all from first/last $\mathrm{COF} / \mathrm{COL}=$ counting on first/last; $\mathrm{df}=$ degrees of freedom

${ }^{a}$ Values of three children were excluded because these children almost always used, counting all-strategies; The correlation changes when only the sums up to 9 are considered, differentiating between small sums such as 2, 3, and 4 and large sums, such as 8, 9-the highest tile in the game shut the box is 9: correlations then are $0.22 ; 0.21 ;-0.26$

larger tally (counting all from last, CAL) (Table 3). Counting further from one dice onwards occurs in $13 \%$ of the actions (47/252); children using this strategy more often use counting further from the larger tally (counting on last, $\mathrm{COL}$ ) then counting further from the smaller tally (counting on first, COF).

The choice of quantifying strategy depends on the sum of the two tallies. The larger the sum, the less often children are using addition $(r=-0.294 ; p<0.001)$ and the more they use counting all $(r=0.216 ; p<0.01)$ or counting on strategies $(r=0.169 ; p<0.01)$ (Table 4$)$. The results are obtained from partial correlations including 246 actions (246/719) that are coded as 'counting all from first/last', 'counting on first/last' or 'addition' (variable 'quantifying strategy') and which refer either to small or to large sums (variable 'sum'). 2, 3, and 4 are considered small sums of the tallies whereas 8, 9, 10, 11 are large sums. Scores of pre-test and post-test are used as a control variable. A supplementary analysis of all actions, which are coded as additions (130/719), demonstrates that the children are employing addition as a quantifying strategy when one of the tallies is $\leq 3$ or if the two tallies are the same.

Assignment of Numbers and Quantities After quantifying, the child is required to compare the different representations of quantities in order to determine whether the tally of either dice or the sum could be used to shut down a tile. This comparison also requires the transfer from iconic or acoustic representation of quantities, to the numerical representation. It is not always necessary to determine the sumsometimes the use of estimations is sufficient. This transfer and the comparison between iconic, acoustic and symbolic representation of the quantity seems not to be difficult to achieve for most children. In $94 \%$ of the 634 episodes, the children determine correctly, whether they can shut down a tile or not. Although it must be said that in situations where a child cannot shut down a tile, it cannot be said with certainty whether number and quantity has in fact been correctly related. Only in 17 actions $(17 / 736)$ did three children count the tiles to determine the right number in episodes with higher numbers $(1 \times 6,7 \times 7,6 \times 8,3 \times 9)$. These children can use the serial position and counting to determine the position of the tile. Counting the tile, however, does not automatically mean that they do not recognise the number. It might also be that they use this action as a control. 
Table 5 Choice of part or sum

\begin{tabular}{lll}
\hline Role of the child & Nonverbal action & Verbal action \\
\hline Player (child 26) & Looks at the dice $(2+4)$ and says, & "I can..." \\
Co-player (child 20) & Interferes early & "Shut down four and two" \\
Player (child 26) & Complements & "Or else" \\
Co-player (child 20) & Answers & "You can add too" \\
Player (child 26) & Asks & "Can I?" \\
Co-player (child 20) & Answers & "Pardon?" [pause] "You can shut six" \\
Player (child 26) & Confirms & "Oh, six." \\
\hline
\end{tabular}

Part-Whole Concept In the version of Shut the Box described for the play-based fostering of mathematics and played by most children only one tile can be shut within one episode. Sometimes there is only one option for the episode or none. Sometimes children need to choose one option out of two or three. From all 634 episodes, 172 actions offered two or three options. Children who often use counting strategies, tend to select the sum, while children who rarely use counting strategies frequently choose the part. Several examples show that some children have fixed preferences for either sum or part; these children tend to then overlook the possible alternative. The example in Table 5 illustrates such an interesting discussion. The player had focussed only on the parts during the last episodes. In this episode he cannot apply this strategy as the two tiles $(2,4)$ are already shut down. He overlooks the other option. His co-player advises him that the sum is also possible. Keeping both possibilities in mind, the sum and the parts, seems to be challenging for some children.

In 64 of the total 634 episodes 77 mistakes were noted. The majority of the mistakes relate to the part-sum selection $(47 / 77)$ or to problems in one-to-one identification while counting the tally or the tiles (19/77). Other counting or addition mistakes only rarely happened. All but two children made mistakes.

\subsection{Correlations Between Strategies and Mathematical Competency}

This chapter addresses the question of whether the quantifying strategies employed in the game Shut the Box relate to the overall maths test score of the children. As already stated, mathematical competency of the children was measured as part of a pre- and post-test design, using the test by Moser and Berweger (2007). The children of the Shut the Box sample had a mean pre-test result of $70.8(\mathrm{SD}=20.6)$ and a mean posttest result of 83.05 ( $\mathrm{SD}=19.1)$. At the level of the individual child, the percentage of actions with counting is determined (Table 6). Results show that some children count almost always (94\% actions with counting), some almost never (7\% actions with counting). The correlation between the percentage of actions with counting as obtained from the video analysis with the mathematics competences is negative and significant (pre-test: $r=-0.360, n=733, p<0.001$; post-test: $r=-0.410, n=$ 733, $p<0.001)$. The children with lower maths competencies according to the test score tend to use counting as a quantifying strategy, whereas children with higher maths competencies count less often and use other quantifying strategies. Differences 
Table 6 Maths competency and percentage of actions with counting

\begin{tabular}{|c|c|c|c|c|c|}
\hline \multirow{2}{*}{$\begin{array}{l}\text { Child (Number) } \\
231\end{array}$} & \multirow{2}{*}{$\begin{array}{l}\text { Maths competency } \\
\text { pre-test }\end{array}$} & \multicolumn{3}{|c|}{$\begin{array}{l}\text { Maths competencE pisode Action } \\
\text { post-test }\end{array}$} & \multirow{2}{*}{$\begin{array}{l}\text { Percentage of actions } \\
\text { with counting }\end{array}$} \\
\hline & & 56 & 20 & 25 & \\
\hline 22 & 35 & 56 & 82 & 98 & 92 \\
\hline 21 & 52 & 67 & 9 & 11 & 82 \\
\hline 27 & 72 & 74 & 20 & 22 & 76 \\
\hline 23 & 68 & 71 & 82 & 87 & 72 \\
\hline 201 & 69 & 66 & 8 & 10 & 70 \\
\hline 241 & 84 & 90 & 9 & 13 & 70 \\
\hline 29 & 46 & 62 & 9 & 9 & 56 \\
\hline 262 & 66 & 73 & 13 & 20 & 55 \\
\hline 271 & 47 & 82 & 20 & 25 & 52 \\
\hline 28 & 71 & 86 & 79 & 84 & 50 \\
\hline 24 & missing & missing & 23 & 24 & 46 \\
\hline 211 & 74 & 83 & 13 & 17 & 35 \\
\hline 212 & 79 & 111 & 17 & 21 & 33 \\
\hline 291 & 103 & 111 & 34 & 49 & 29 \\
\hline 30 & 49 & 70 & 75 & 80 & 26 \\
\hline 25 & 90 & 107 & 24 & 28 & 25 \\
\hline 281 & 82 & 94 & 33 & 40 & 22 \\
\hline 261 & 75 & 81 & 13 & 18 & 10 \\
\hline 20 & 120 & 120 & 25 & 29 & 10 \\
\hline 26 & 83 & 101 & 26 & 29 & 7 \\
\hline Total & & & 634 & 739 & \\
\hline
\end{tabular}

Note. Children in descending order of the percentage of actions with counting

could also be found with regards to the counting strategies: children with lower maths competencies according to test score use CAF and CAL counting strategies, children with higher competencies use COF and COL strategies more often or exclusively.

Focussing on the situations where the tally cannot be used to shut down a tile because all three possible numbers have already been shut down (338/719), the expected differences can be found between children with lower and higher arithmetic competencies: Children with high arithmetic competencies choose not to count or add up, when they have only few tiles left (Fig. 2); they react very quickly and say for example 'I cannot do anything' or 'your turn'. Children with lower mathematical competencies will still count towards the end of the round, when only one number tile still remains.

\subsection{Playing and Support}

The game Shut the Box is mostly played by two children. To keep the game going, they support each other while playing. 


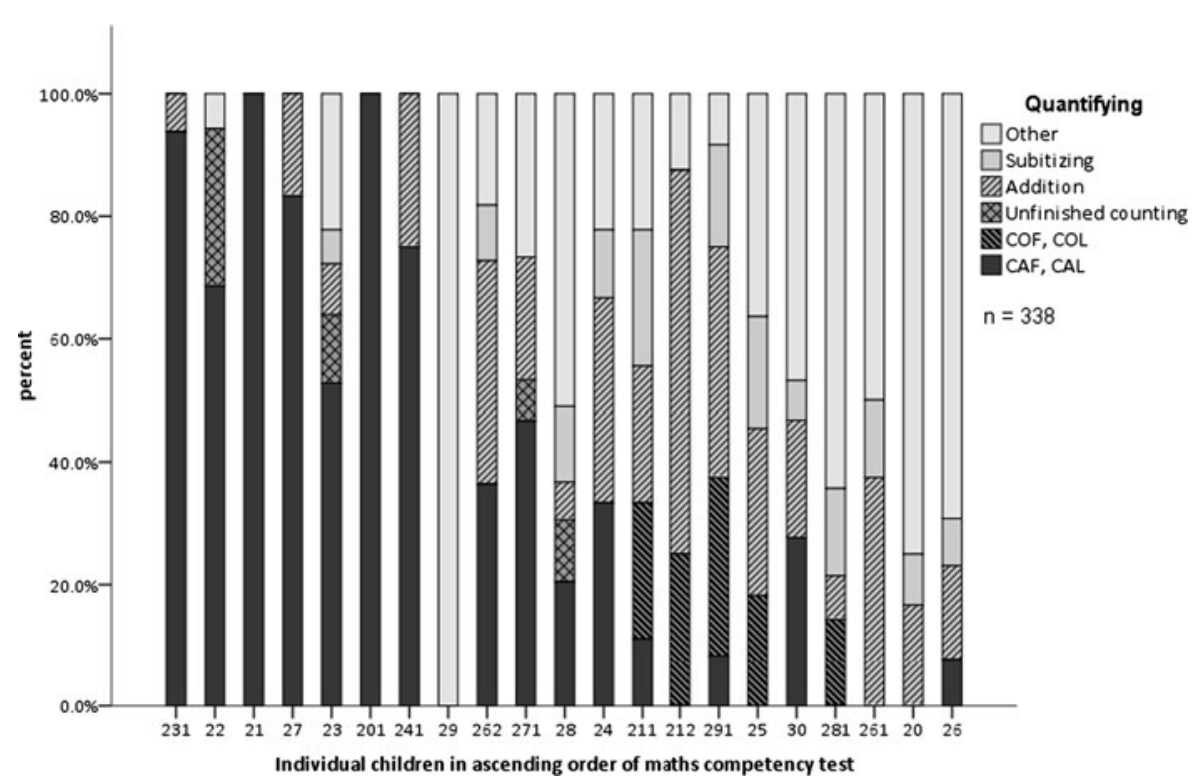

Fig. 2 Percentages of quantifying strategies per child in cases where no number tile could be shut down. Children with lower maths competency towards the left. $\mathrm{CAF} / \mathrm{CAL}=$ counting all from first/last; $\mathrm{COF} / \mathrm{COL}=$ counting on first/last; $n=$ actions

In the analysed videos all children are playing and show high levels of activation. All children are active. The net playtime is very high. Activities other than playing the game, such as waiting for the kindergarten teacher to come, or searching for dice, have only rarely occurred during the videoed sessions. The children have understood the rules of the game and most of the time adhered to them. Approximately $10 \%$ of episodes $(65 / 634)$ and a part of all groups involve parallel play. Only 31 cheating actions or $4 \%$ of all actions are noted. Half of the children never cheated. The majority of cheating includes throwing the dice twice $(24 / 31)$.

For a more detailed analysis of the support the monitoring by the co-player as well as the verbal interaction was coded. However, the content of these interactions was not rated. The data therefore does not allow an interpretation about the quality and the coherence of the peer interaction.

Monitoring For 620 of total 634 episodes the monitoring was coded. The co-player observes during $74 \%$ of the episodes fully or partly the actions of the player. In $16 \%$ of the episodes the co-player looks at his or her own Shut the Box and for $10 \%$ of the episodes they look at something outside the game. During the round, the monitoring changes. The co-player looks more often on his or her own Shut the Box (episodes 1 to 5: $9 \%$ glance on own Shut the Box; episode 9 to 13:17\%) and less often on the action of the player (episode 1 to 5: $81 \%$; episode 9 to 13: $74 \%$ ) as the game processes. The instances of glance outside of the game did not change during the round (episode 1 to 5: $9 \%$; episode 9 to 13: $10 \%$ ). Although the children monitor each other quite closely, they often did not mention mistakes or cheating. In approximately $15 \%$ of the coded episodes (92/620) there was a problem (mistake and/or 
Table 7 Verbalisation of part-sum mistake

\begin{tabular}{lll}
\hline Role child & Nonverbal action & Verbal action \\
\hline Player (child 26) & $\begin{array}{l}\text { Looks carefully at the tallies }(1,4) \text { and says: } \\
\text { (overlooking the part) }\end{array}$ & "I can't" \\
Co-player (child 20) & Reacts & "You can do 1 or... "[pause]" \\
Player (child 26) & Shuts number 1 tile. & $\begin{array}{l}1 \text { you can shut down!" } \\
\text { "Hmm" }\end{array}$ \\
\hline
\end{tabular}

cheating). In one out of four instances (25/92) the problem was mentioned. One such example is shown in Table 7 . In the remaining episodes mistakes or cheating were not verbalised. It could be that some mistakes were not noticed, and it is also possible that some mistakes were not mentioned in order to increase one's own chances for winning.

Verbal Interaction In each episode amount and function of turns were coded. Function codes were given for a statement, a comment or a dialogue. Statements and comments consist of one turn. Statements are verbalisations of the player; they might be part of thinking aloud or talking to oneself for self-regulation. Comments are verbalisations of the co-player. Dialogues include at least two connected verbalisations. Distinguishing these codes was difficult, as children often communicate non-verbally. Approximately a quarter of the episodes (166/634) have no verbalisations except for quantifying aloud. In $37 \%$ of the episodes a statement of the player occurs $(183 / 634)$ or a comment of the co-player (52/634). In $37 \%$ of the episodes $(233 / 634)$ dialogues occur, and in four of these episodes the kindergarten teacher is also engaged. In the majority of cases, the player initiates the verbal interaction. Therefore, the children are more active in verbalising when in the role of the player than of the co-player. Dialogues are generally short. Approximately $60 \%$ of the dialogues $(133 / 229)$ consist of two turns and $20 \%$ include three turns (44/229) or four and more turns $(52 / 229)$.

Finally, in 634 episodes a total of 896 turns were analysed to determine content of verbalisations. As Fig. 3 shows, the children exclusively talk about content related to mathematics or the game. Other verbalisations are rare. The largest part of verbalisations relate to assignment of number and quantities.

\section{Discussion}

Basics of individual mathematical competency develop informally before children enter kindergarten. At the beginning of kindergarten children differ greatly in their mathematical knowledge and skills. Early quantity-number competencies have been described as determinative precursors for a successful development of later arithmetic abilities. To give equal opportunities to all children, a variety of programmes aimed at fostering quantity-number competencies have been developed and successfully implemented in kindergarten classes in recent years. Unfortunately most of these programmes involve formal instruction and therefore do not fit easily into the learning 
Fig. 3 Percentage of the contents of students' turns. Each turn in the 634 episodes was assigned a main content $(n=896)$

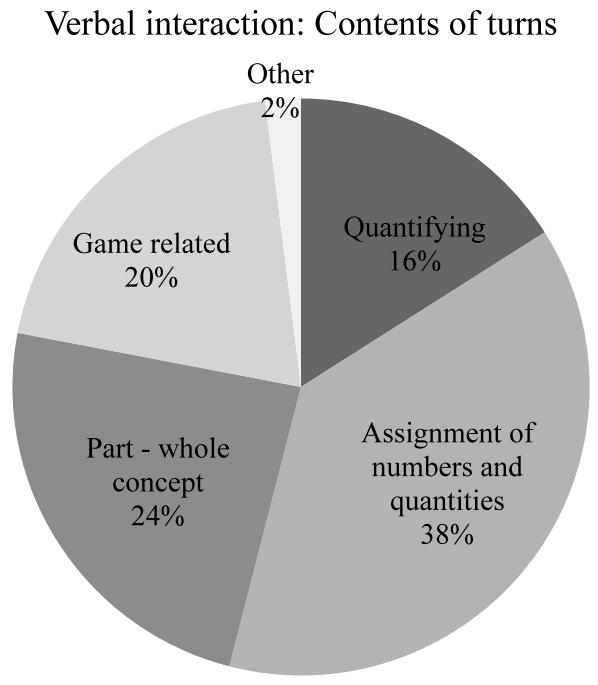

cultures in Swiss kindergarten. In German speaking Switzerland, pedagogy in kindergarten is strongly related to the concept of free play. Play rather than school-like formal instruction could, however, very well be beneficial for fostering mathematical precursory competencies. A variety of studies has examined the effectiveness of a board or card game for fostering mathematical competencies.

Knowing that children enjoy playing games and engage in many different types of mathematical ideas during play, a play-based mathematical fostering ( $\mathrm{SpiF}$ ) with card and board games to foster quantity-number competencies was developed and implemented. In order to find out whether the selected games promote the intended quantity-number competencies children were videoed while playing in small groups. In this article the analysis of the board game Shut the Box is presented. The analysis includes the aspects of mathematics behaviour (content), playing (method) and peer interaction.

Regarding the mathematical behaviour shown while playing the game Shut the box a great variety of strategies could be found. Often, the sum was determined through counting all from first (CAF) or counting all from last (CAL), as well as through subitizing and addition. While playing Shut the Box, most of the children made relatively few mistakes. As two thirds of all mistakes concern part-sum mistakes, we suppose that the simultaneous monitoring of sum and parts poses a challenge for most children of kindergarten age. The game Shut the box could be seen as a good teaching and learning arrangement for the simultaneous monitoring of sum and parts as well as an opportunity to develop quantifying strategies. Clearly, the strategies used depend on the tally and on the mathematical competences of the child. Correlations could be found between strategies and test scores. Children with higher test scores use strategies without counting more often. The analysis of play and support given by the children in their peer interaction shows that almost all children understood the rules and procedures of the game and were able to participate regardless of their arithmetic competencies. However, co-players often overlooked mistakes. We assume that it is more difficult for the children to observe the actions of the co-player 
than to perform an action themselves. While the children talked quite a lot during the game, discussions focussed primarily on the game and arithmetic operations. Other things were rarely mentioned or discussed. The children were primarily engaged in playing Shut the Box, and consequently, we conclude that the task orientation was high.

For teaching and learning, characteristics of meaningful learning tasks were highlighted: Emphasising the different strategies, adaptive learning task, activation and motivation as well as co-operative learning. As a conclusion from the exploratory video analysis these aspects can be met with the game Shut the box:

- The board game Shut the Box supports a variety of mathematical strategies, from relying on counting by touching through to subitizing and additions. This allows for children to play the game at their individual competency level, using appropriate strategies, repeating and expanding their strategies. The analysis showed that the choice of strategies was related to the tallies of the dice: lower sums were addressed with other strategies compared to larger sums. We conclude that most children were challenged, but not overstretched through the game at the time of playing. However, only a video study with longitudinal design would capture the development of each child's skills and strategies and could also explain the differences in the learning outcomes amongst the children.

- The game Shut the Box proves to be an adaptive and meaningful learning task: also children with diverging arithmetic competencies are able to play the game together. The rules of the games are easy to understand and there is little conflict amongst the players as to how to apply them. An important aspect of the quality of a learning game is also met: the actions while playing Shut the Box are determined by rules, regulating what to do, but the strategies are open-several strategies are possible. Each individual child therefore can choose a strategy according to his or her individual level of competencies. As a result, a rich variety of strategies could be observed in the video data.

- Children playing Shut the Box show very high motivation and time on task: The game is popular amongst the children, thus they repeated the game, they focussed their attention on the game and they kept the play going. The time is devoted to playing. The children are primarily concerned with their actions, almost exclusively discuss arithmetic or game related issues, and their attention is only rarely diverted. We assume that playing games is possibly more motivating than more instructional settings and that the peer collaboration is part of the motivating aspects of this teaching and learning arrangement

- The children play collaboratively. The video data shows many incidents where children support each other, give verbal explanations for their actions and discuss arithmetic themes. They were most active in the role of the player. According to Sfard and Lavie (2005) numerical communication can be internalised through repeated discussions and thereby contributes to developing a deeper understanding. This can be a foundation for further constructions of knowledge by the child as the child interacts with his or her surroundings.

As the analysis presented here is of exploratory nature only, the results should be interpreted with caution and cannot be generalised. For further insights into the 
learning processes and the scope of board and card games for early mathematics, the videos of other games also need to be analysed. This first exploratory analysis leads us to the hypothesis that board games like Shut the Box can provide a high quality teaching and learning arrangement, offering cognitively activating and challenging learning tasks, adaptive for different levels of mathematical competencies and allowing for diverse strategies, embedded in a collaborative setting. More research is necessary on the exact ways such teaching and learning arrangements support mathematical learning.

Acknowledgement This research project was funded by the Swiss National Science Foundation (Project 100014_124485, 2009-2011). We also thank the participating teachers and children as well as the reviewers of this paper for their helpful and appreciated comments.

\section{References}

Ainley, J. (1990). Playing games and learning mathematics. In L. P. Steffe \& T. Wood (Eds.), Transforming children's mathematics education: international perspectives (pp. 84-91). Hillsdale: Erlbaum.

Ashcraft, M. (1995). Cognitive psychology and simple arithmetics. A review and summary of new directions. Mathematical Cognition, 1, 3-34.

Aunio, P., Hautamäki, J., Sajaniemi, N., \& van Luit, J. E. H. (2009). Early numeracy in low-performing young children. British Educational Research Journal, 35(1), 25-46.

Baroody, A. J. (1995). The role of the number-after rule in the invention of computational shortcuts. Cognition \& Instruction, 13(2), 189-219.

Blömeke, S., Risse, J., Müller, C., Eichler, D., \& Schulz, W. (2006). Analyse der Qualität von Aufgaben aus didaktischer und fachlicher Sicht. Ein allgemeines Modell und seine exemplarische Umsetzung im Unterrichtsfach Mathematik. Unterrichtswissenschaft, 34(4), 330-357.

Boonen, A. J. H., Kolkman, M. E., \& Kroesbergen, E. H. (2011). The relation between teachers' math talk and the acquisition of number sense within kindergarten classrooms. Journal of School Psychology, 49(3), 281-299.

Bragg, L. A. (2003). Children's perspectives on mathematics and game playing. In L. Bragg, C. Campbell, G. Herbert, \& J. Mousley (Eds.), MERINO: mathematics education research: innovation, networking, opportunity. Proceedings of the 26th annual conference of the mathematics education research group of Australasia (Vol. 2, pp. 160-167). Geelong: Merga.

Bright, G. W., Harvey, J. G., \& Montague Wheeler, M. (1985). Learning and mathematics games. Journal for Research in Mathematics Education, 1(1), 1-189.

Clements, D. H. (1999). Subitizing: What is it? Why teach it? Retrieved [October 15, 2012] from http://gse.buffalo.edu/fas/clements/files/Subitizing.pdf.

Dehaene, S. (1997). The number sense: how the mind creates mathematics. New York: Oxford University Press.

Dollase, R. (2010). Verschulung oder Kuschelpädagogik: wann ist Vorschulerziehung effektiv? In D. H. Rost (Ed.), Intelligenz, hochbegabung, vorschulerziehung, bildungsbenachteiligung (pp. 125-164). Münster: Waxmann.

Fogelman, K. (Ed.) (1983). Growing up in great Britain: papers from the national child development study. London: Macmillan.

Friedrich, G., de Galgóczy, V., \& Schindelhauer, B. (2011). Komm mit ins Zahlenland. Freiburg: Herder Verlag. Revised edition.

Gelman, R., \& Gallistel, C. (1978). The child's understanding of number. Cambridge: Harvard University Press.

Gillies, R. M., \& Haynes, M. (2011). Increasing explanatory behaviour, problem-solving, and reasoning within classes using cooperative group work. Instructional Science, 39(3), 349-366.

Ginsburg, H. P., \& Golbeck, L. S. (2004). Thoughts on the future of research on mathematics and science learning and education. Early Childhood Research Quarterly, 19(1), 190-200.

Ginsburg, H. P., Lee, J. S., \& Stevenson Boyd, J. (2008). Mathematics education for young children: what it is and how to promote it. Social Policy Report, XXII(1), 3-22. 
Golinkoff, R. (2010). The power of play: preparing 21 st century children for a global world. Paper presented at the EARLS SIG5 meeting 26/08/2010, Luzern.

Griffin, S. (2004). Building number sense with number worlds: a mathematics program for young children. Early Childhood Research Quarterly, 19(1), 173-180.

Grüßing, M., \& Peter-Koop, A. (2008). Effekte vorschulischer mathematischer Förderung am Ende des ersten Schuljahres. Erste Befunde einer Längsschnittstudie. Zeitschrift für Grundschulforschung, 1(1), $65-82$.

Hauser, B. (2013). Spielen. Frühes Lernen in Familie, Krippe und Kindergarten. Stuttgart: Kohlhammer.

Hauser, B. (2005). Das Spiel als Lernmodus: unter Druck von Verschulung - im Lichte neuerer Forschung. In T. Guldimann \& B. Hauser (Eds.), Bildung 4- bis 8-jähriger Kinder (pp. 143-168). Münster: Waxmann.

Hauser, B., Vogt, F., Stebler, R., Rechsteiner, K., \& Lehner, R. (2010). Mathematics in Kindergarten: teacher-directed training programmes or play-based approaches? Paper presented at the EARLI-SIG5 meeting ,learning and development in early childhood“", 25/08/2010, Luzern.

Helmke, A., \& Weinert, F. E. (1997). Bedingungsfaktoren schulischer Leistungen. In F. E. Weinert (Ed.), Psychologie des Unterrichts und der Schule. Enzyklopädie der Psychologie. Themenbereich D, Serie I (Vol. 3, pp. 71-176). Göttingen: Hogrefe.

Hengartner, E., \& Roethlisberger, H. (1995). Rechenfähigkeit von Schulanfängern. In H. Brügelmann, H. Balhorn, \& I. Füssenich (Eds.), Am Rande der Schrift. Zwischen Sprachenvielfalt und Analphabetismus (pp. 66-86). Beinwil am See: Libelle Verlag.

Hirschmann, N., Kastner-Koller, U., \& Deimann, P. (2008). Entwicklung und Diagnostik mathematischer Fähigkeiten in der frühen Kindheit. Empirische Pädagogik, 22(2), 178-192.

Hopkins, S., \& Lawson, M. J. (2002). Explaining the acquisition of a complex skill: methodological and theoretical considerations uncovered in the study of simple addition and the moving-on process. Educational Psychology Review, 14(2), 121-154.

Howe, C., Tolmie, A., Thurston, A., Topping, K., Christie, D., Livingston, K., Jessiman, E., \& Donaldson, C. (2007). Group work in elementary science: towards organisational principles for supporting pupil learning. Learning and Instruction, 17(5), 549-563.

Hughes, M. (1986). Children and number: difficulties in learning mathematics. London: Blackwell.

Jordan, N. C., Glutting, J., \& Ramineni, C. (2010). The importance of number sense to mathematics achievement in first and third grades. Learning and Individual Differences, 20(2), 82-88.

Jordan, N. C., Kaplan, D., Ramineni, C., \& Locuniak, M. N. (2009). Early math matters: kindergarten number competence and later mathematics outcomes. Developmental Psychology, 45(3), 850-867.

Kamii, C., \& Kato, Y. (2005). Fostering the development of logico-mathematical thinking in a card game at ages 5-6. Early Education \& Development, 16(3), 367-383.

Krajewski, K., \& Schneider, W. (2009). Exploring the impact of phonological awareness, visual-spatial working memory, and preschool quantity-number competencies on mathematics achievement in elementary school: findings from a 3-year longitudinal study. Journal of Experimental Child Psychology, 103(4), 516-531.

Krajewski, K., \& Schneider, W. (2006). Mathematische Vorläuferfertigkeiten im Vorschulalter und ihre Vorhersagekraft für die Mathematikleistungen bis zum Ende der Grundschulzeit. Studienhefte Psychologie in Erziehung und Unterricht, 53(4), 246-262.

Krajewski, K., Nieding, G., \& Schneider, W. (2008). Kurz- und langfristige Effekte mathematischer Frühförderung im Kindergarten durch das Programm „Mengen, zählen, Zahlen“. Zeitschrift für Entwicklungspsychologie und Pädagogische Psychologie, 40(3), 135-146.

Krajewski, K., Nieding, G., \& Schneider, W. (2007). Mengen, zählen, Zahlen: die Welt der Mathematik verstehen (MzZ). Berlin: Cornelsen.

Marcon, R. (2002). Moving up the grades: relationship between pre-school model and later school success. Early Childhood Research and Practice, 4(1). Retrieved [October 15, 2012] from http://ecrp.uiuc.edu/v4nl/marcon.html

Mayring, P. (2007). Qualititative Inhaltsanalyse. Grundlagen und Techniken (9th ed.). Weinheim und Basel: Beltz Verlag.

McConkey, R., \& McEvoy, J. (1986). Games for learning to count. British Journal of Special Education, $13(2), 59-62$.

Moser Opitz, E. (2001). Zählen, Zahlbegriff, Rechnen: Theoretische Grundlagen und eine empirische Untersuchung zum mathematischen Erstunterricht in Sonderklassen. Bern: Haupt.

Moser, U., \& Bayer, N. (2010). Schlussbericht der summativen Evaluation. In Lernfortschritte vom Eintritt in die Eingangsstufe bis zum Ende der 3. Klasse der Primarschule. Erziehung und Bildung in 
Kindergarten und Unterstufe im Rahmen der EDK-Ost und Partnerkantone (Projekt EDK-Ost 4bis8). Bern: Schulverlag.

Moser, U., \& Berweger, S. (2007). Wortgewandt \& zahlenstark. Lern- und Entwicklungsstand bei 4- bis 6-Jährigen. St. Gallen: Lehrmittel der interkantonalen Lehrmittelzentrale ilz.

Moser, U., Stamm, M., \& Hollenweger, J. (Eds.) (2005). Für die Schule bereit? Lesen, Wortschatz, Mathematik und soziale Kompetenzen beim Schuleintritt. Oberentfelden: Sauerländer.

Obersteiner, A. (2012). Mentale Repräsentationen von Zahlen und der Erwerb arithmetischer Fähigkeiten. Konzeptionierung und Evaluation einer Förderung mit psychologisch-didaktischer Grundlegung und Evaluation im ersten Schuljahr. Münster: Waxmann.

Osana, H. P., \& Rayner, V. (2010). Developing numeracy: promoting a rich learning environment for young children. In Encyclopedia of language and literacy development (pp. 1-12). London: Canadian Language and Literacy Research Network. Retrieved [October 15, 2012] from http://www.literacyencyclopedia.ca/pdfs/topic.php?topId=286.

Pauen, S., \& Pahnke, J. (2008). Mathematische Kompetenzen im Kindergarten: Evaluation der Effekte einer Kurzzeitintervention. Empirische Pädagogik, 22(2), 193-208.

Peters, S. (1998). Playing games and learning mathematics: the results of two intervention studies. International Journal of Early Years Education, 6(1), 49-58.

Deutschschweizer Lehrplan, P. (2010). Grundlagen für den Lehrplan 21 verabschiedet von der Plenarversammlung der deutschsprachigen EDK-Regionen am 18. März 2010 Luzern: Geschäftsstelle der deutschsprachigen EDK-Regionen. Retrieved [October 15, 2012] from http://web.lehrplan.ch/ sites/default/files/Grundlagenbericht.pdf.

Ramani, G. B., \& Siegler, R. S. (2011). Reducing the gap in numerical knowledge between low- and middle-income preschoolers. Journal of Applied Developmental Psychology, 32(3), 146-159.

Rechsteiner, K., Hauser, B., \& Vogt, F. (2012). Förderung der mathematischen Vorläuferfertigkeiten im Kindergarten: Spiel oder Training? In M. Ludwig \& M. Kleine (Eds.), Beiträge zum Mathematikunterricht 2012 (Vol. 2, pp. 677-680). Münster: WTM Verlag für wissenschaftliche Texte und Medien. http://www.mathematik.uni-dortmund.de/ieem/bzmu2012/index.html.

Resnick, L. R. (1989). Developing Mathematical Knowledge. The American Psychologist, 44(2), 162169.

Reusser, K. (2011). Unterricht und Klassenführung. In L. Criblez, B. Müller, \& J. Oelkers (Eds.), Die Volksschule zwischen Innovationsdruck und Reformkritik (pp. 68-83). Zürich: Neue Zürcher Zeitung NZZ Libro.

Reusser, K. (2006). Konstruktivismus - vom epistemologischen Leitbegriff zur Erneuerung der didaktischen Kultur. In M. Baer, M. Fuchs, P. Füglister, K. Reusser, \& H. Wyss (Eds.), Didaktik auf psychologischer Grundlage. Von Hans Aeblis kognitionspsychologischer Didaktik zur modernen Lehr- und Lernforschung (pp. 151-168). Bern: h.e.p.

Reusser, K. (2001). Co-constructivism in educational theory and practice. In N. J. Smelser, P. B. Baltes, \& F. E. Weinert (Eds.), International encyclopedia of the social and behavioral sciences (pp. 20582062). Oxford: Pergamon.

Reusser, K., \& Stebler, R. (2012). Differenzierende Unterrichtsangebote für individualisiertes Lernen. Zürcher Lehrerinnen- und Lehrerverband, 5, 6-9.

Schuler, S. (2013). Mathematische Bildung im Kindergarten in formal offenen Situationen - eine Untersuchung am Beispiel von Spielen zum Erwerb des Zahlbegriffs. Münster: Waxmann.

Sfard, A., \& Lavie, I. (2005). Why cannot children see as the same what grown-ups cannot see as different? Early numerical thinking revisited. Cognition and Instruction, 23(2), 237-309.

Siegler, R. S., Fazio, L. K., \& Pyke, A. (2011). There is nothing so practical as a good theory. In J. P. Mestre \& B. H. Ross (Eds.), The psychology of learning and motivation: Vol. 55. Cognition in education (pp. 171-197). Oxford: Elsevier.

Singer, D., Michnik Golinkoff, R., \& Hirsh-Pasek, K. (2009). Play = learning: how play motivates and enhances children's cognitive and social-emotional growth. Oxford: University Press.

Van Oers, B. (2010). Emergent mathematical thinking in the context of play. Educational Studies in Mathematics, 74(1), 23-37.

Vogt, F. (2012). Play-based mathematics in kindergarten. Paper presented at POEM Conference, Frankfurt, a. M. 27th February 2012.

Vygotsky, L. S. (1978). Mind in society: the development of higher psychological processes. Cambridge: Harvard University Press.

Weinhold Zulauf, M., Schweiter, M., \& von Aster, M. (2003). Das Kindergartenalter: Sensitive Periode für die Entwicklung numerischer Fertigkeiten. Kindheit und Entwicklung, 12(4), 222-230. 
Whyte, J. C., \& Bull, R. (2008). Number games, magnitude representation, and basic number skills in preschoolers. Developmental Psychology, 44(2), 588-596.

Wikipedia (2012). Shut the box. Retrieved [October 15, 2012] from http://en.wikipedia.org/wiki/Shut_ the_Box.

Wittmann, E. C. (2010). Grundsätzliche Überlegungen zur frühkindlichen Bildung in der Mathematik. In M. Stamm \& D. Edelmann (Eds.), Frühkindliche Bildung, Betreuung und Erziehung. Was kann die Schweiz lernen? (pp. 177-195). Zürich: Rüegger.

Wittmann, E. C. (2009). Das Zahlenbuch Frühförderung. Stuttgart: Klett.

Wolf, I. (2011). Förderung arithmetischer Kompetenzen durch Regelspiele in Kindergarten am Beispiel „Shut the Box“. Mikrogenetische Videostudie zu Anwendung arithmetischer Kompetenzen und Interaktion im Spiel. Unveröffentlichte Lizentiatsarbeit, Universität Zürich.

Wood, E. (2011). Entwicklung einer integrierten Pädagogik für die frühe Bildung. In F. Vogt, M. Leuchter, A. Tettenborn, U. Hottinger, M. Jäger, \& E. Wannack (Eds.), Entwicklung und Lernen junger Kinder (pp. 123-133). Münster: Waxmann. 